\title{
The role of ADAMTSs in arthritis
}

\author{
Edward A. Lin ${ }^{1}$, Chuan-Ju Liu ${ }^{1,2}(\bowtie)$ \\ ${ }^{1}$ Department of Orthopaedic Surgery, New York University School of Medicine, New York, NY 10003, \\ USA \\ 2 Department of Cell Biology, New York University School of Medicine, New York, NY 10016, USA \\ $\triangle$ Correspondence: chuanju.liu@med.nyu.edu
}

Received September 14, 2009; accepted October 21, 2009

\begin{abstract}
The ADAMTS (a disintegrin and metalloproteinase with thrombospondin motifs) family consists of 19 proteases. These enzymes are known to play important roles in development, angiogenesis and coagulation; dysregulation and mutation of these enzymes have been implicated in many disease processes, such as inflammation, cancer, arthritis and atherosclerosis. This review briefly summarizes the structural organization and functional roles of ADAMTSs in normal and pathological conditions, focusing on members that are known to be involved in the degradation of extracellular matrix and loss of cartilage in arthritis, including the aggrecanases (ADAMTS-4 and ADAMTS-5), ADAMTS-7 and ADAMTS12 , the latter two are associated with cartilage oligomeric matrix protein (COMP), a component of the cartilage extracellular matrix (ECM). We will discuss the expression pattern and the regulation of these metalloproteinases at multiple levels, including their interaction with substrates, induction by pro-inflammatory cytokines, protein processing, inhibition (e.g., TIMP-3, alpha-2macroglobulin, GEP), and activation (e.g., syndecan-4, PACE-4).
\end{abstract}

KEYWORDS ADAMTS, metalloproteinase, aggrecan, COMP, arthritis

\section{INTRODUCTION}

Arthritis is a disease characterized by damage of joints, which leads to chronic debilitating pain and stiffness. Two of the most common forms, osteoarthritis and rheumatoid arthritis, combine to affect more than 28 million Americans; they exact a significant toll on our society, both in terms of financial cost and disease morbidity. Osteoarthritis (OA), which is the most common form of arthritis, is characterized by the progressive loss of articular hyaline cartilage (leading to narrowing of the joint space) along with underlying bony changes surrounding the joint (i.e., osteophytes, sclerosis and subchondral cysts). Rheumatoid arthritis (RA) is an autoimmune condition that can be described as a chronic inflammatory polyarthritis with progressive erosion of tissues within and surrounding the joint. The destruction of articular cartilage is a feature of both $\mathrm{OA}$ and $\mathrm{RA}$, and is thought to involve the proteolytic degradation of extracellular matrix (ECM) components. The a disintegrin and metalloproteinase with thrombospondin motifs (ADAMTS) family of secreted zinc metalloproteinases includes many members that are known to bind and degrade extracellular matrix components. First identified in 1997, the ADAMTS family has since grown to 19 members, and has been implicated in diseases ranging from coagulation disorders to malignancy (Levy et al., 2001; Barreda et al., 2004; Porter et al., 2005; Llamazares et al., 2007; Roy et al., 2008; Apte, 2009). The important roles of ADAMTSs in osteoarthritis and rheumatoid arthritis have been well established (Clark and Parker, 2003; Jones and Riley, 2005; Murphy and Lee, 2005; Burrage et al., 2006; Fosang et al., 2008; Murphy and Nagase, 2008; Rowan et al., 2008; Liu, 2009). However, despite significant advances in knowledge regarding the structure and function of ADAMTS metalloproteinases, the exact mechanistic involvement of these molecules in the pathogenesis of arthritis has yet to become fully elucidated. In this review, we summarize what is currently known about various members of the ADAMTS family of metalloproteinases as they relate to the joint destructive processes of arthritis. 


\section{ADAMTSS-STRUCTURE BASED ON FUNCTION}

ADAMTSs, which can occur in multiple isoforms due to alternative splicing, are translated initially as inactive preproenzymes, whose structure includes a signal peptide, a pro-domain, a catalytic domain, a disintegrin-like domain, a central thrombospondin type I-like (TS) repeat, a cysteine-rich domain, a spacer region, and a variable number of C-terminal TS repeats (Kuno et al., 2000; Tang, 2001; Apte, 2004) (Fig. 1). Although the ADAMTS catalytic domain shares structural similarity with that of matrix metalloproteinases (MMPs), MMPs do not share the other structural features of the ADAMTS family. The C-terminal TS repeats, the number of which may vary from 14 (ADAMTS-20) (Llamazares et al., 2003; Somerville et al., 2003) to none (ADAMTS-4) (Tortorella et al., 1999), seem to be important for the ability of many ADAMTS members to bind components of ECM (Kuno et al., 2000; Tortorella et al., 2000a; Hashimoto et al., 2004). ADAMTS-4, which contains no C-terminal TS repeats, is able to bind to ECM components via its C-terminal spacer region (which associates with the $\mathrm{C}$-terminal domain of fibronectin) (Hashimoto et al., 2004) (Fig. 1). The ADAMTSs undergo $\mathrm{N}$-terminal processing, with removal of the signal sequence followed by removal of the pro-domain, which involves a furin cleavage site (with the exception of ADAMTS10 and -12) (Bergeron et al., 2000). Interestingly, ADAMTS-13 can be active with the pro-domain still attached (Majerus et al., 2003; Somerville et al., 2004). The ADAMTSs also undergo C-terminal processing, which involves cleavage within the spacer region (Rodriguez-Manzaneque et al., 2000; Flannery et al., 2002; Gao et al., 2002; Luque et al., 2003; Majerus et al., 2003; Gao et al., 2004). Such processing is important for both substrate specificity and localization of the enzymes (Porter et al., 2005).
ADAMTS proteins are divided into four divisions, based on structural and functional similarities (Thompson et al., 1994; Llamazares et al., 2003; Nicholson et al., 2005). These divisions can be further broken down into subgroups. One sub-group consists of ADAMTS-1, $-4,-5,-8$, and -15 , while another includes ADAMTS-9 and -20 . Both sub-groups combine to form a larger division. Another division consists of ADAMTS-2, -3 , and -14 . ADAMTS-13 forms its own division. The remaining ADAMTS members form their own division, which is divided into structurally-related pairs: ADAMTS-17 and -19, ADAMTS-16 and -18, ADAMTS-7 and -12 , and ADAMTS-6 and -10 .

\section{ADAMTSs-NOT JUST ARTHRITIS}

Members of the ADAMTS family have been implicated in a wide range of diseases (Table 1). ADAMTS-13 plays a role in the development of the coagulation disorder, thrombotic thrombocytopenic purpura (Levy et al., 2001; Hovinga et al., 2004; Moake, 2004; Shenkman, 2006). Patients with Ehler-Danlos syndrome type 7C, a genetic disorder of collagen synthesis, have mutations in the ADAMTS-2 gene (Colige et al., 1999, 2004). These mutations have also been associated with bovine dermatopraxis, an inherited disorder characterized by severe skin fragility (Colige et al., 1999). ADAMTS-1 exhibits angioinhibitory properties and is crucial for the development and function of the urogenital system (Shindo et al., 2000; Nakamura et al., 2007; Basile et al., 2008). ADAMTS-1 may also contribute to atherosclerosis by cleaving versican (Jonsson-Rylander et al., 2005). Mutations in ADAMTS-1 have been associated with an increased risk of coronary artery disease (Sabatine et al., 2008). Other ADAMTSs, including ADAMTS-4, -7, and -8, have also been implicated in the formation of

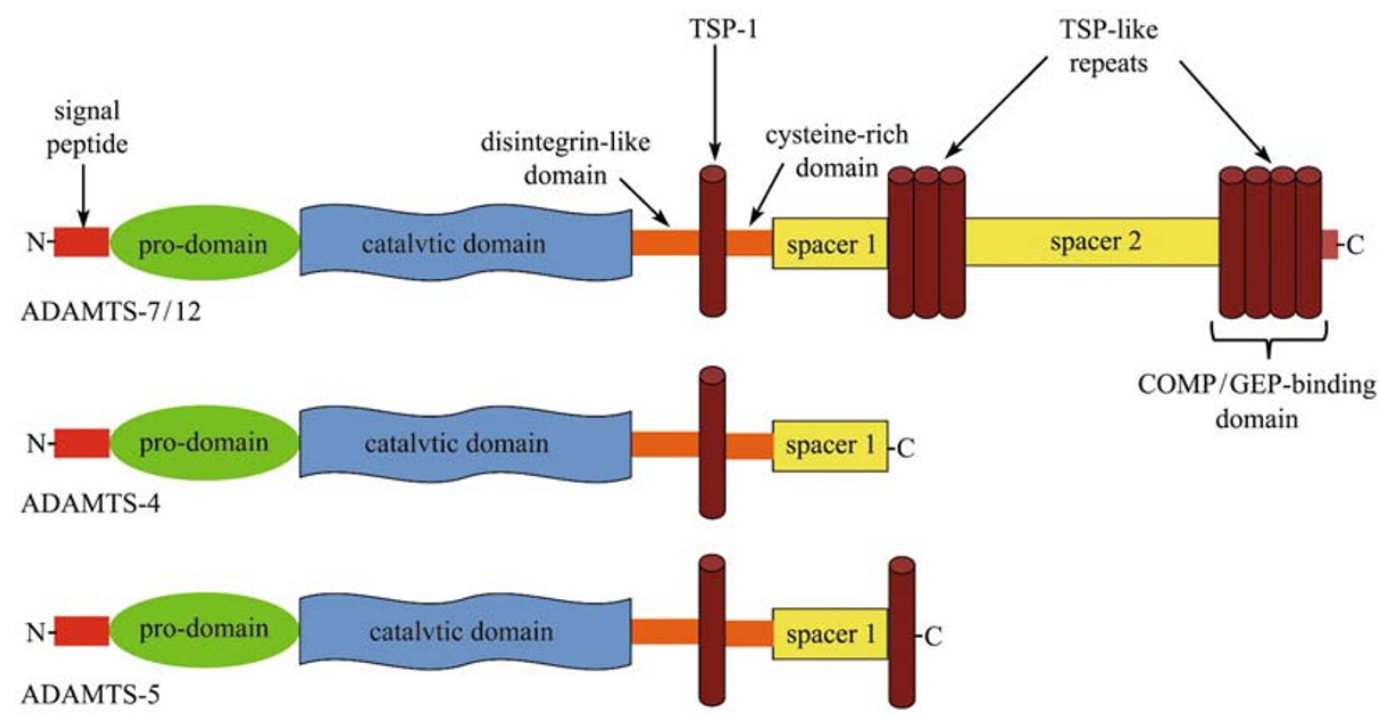

Figure 1. Schematic representation of the domain organization of ADAMTS-4, -5, -7, and $-\mathbf{1 2}$. The COMP- and GEP-binding domain is indicated. 
Table 1. Summary of the ADAMTS family

\begin{tabular}{|c|c|c|c|}
\hline ADAMTS & alternative name(s) & known substrate(s) & role in disease \\
\hline 1 & METH-1 & aggrecan, versican & $\begin{array}{l}\text { anti-angiogenic (Vazquez et al., 1999) } \\
\text { renal interstitial fibrosis (Mittaz et al., 2005; } \\
\text { Nakamura et al., 2007) } \\
\text { bone remodeling (Lind et al., 2005; Rehn et al., } \\
2007 \text { ) } \\
\text { ovarian folliculogenesis (Shozu et al., 2005; } \\
\text { Brown et al., 2006) } \\
\text { atherosclerosis (Jonsson-Rylander et al., 2005) } \\
\text { urogenital development (Mittaz et al., 2004) } \\
\text { tumor growth/remodeling (Rocks et al., 2008) }\end{array}$ \\
\hline 2 & PCINP & collagen I, II, III N-propeptides & $\begin{array}{l}\text { Ehler-Danlos syndrome type 7C (Colige et al., } \\
\text { 1999, 2004) } \\
\text { bovine dermatopraxis (Colige et al., 1999) }\end{array}$ \\
\hline 3 & KIAA0366 & procollagen II N-propeptide & \\
\hline 4 & aggrecanase-1 & $\begin{array}{l}\text { aggrecan, brevican, COMP, decorin, } \\
\text { fibromodulin, versican }\end{array}$ & $\begin{array}{l}\text { arthritis (Bau et al., 2002; Plaas et al., 2007; Song } \\
\text { et al., 2007), atherosclerosis }\end{array}$ \\
\hline 5 & aggrecanase-2, ADAMTS-11 & aggrecan, $\alpha 2 \mathrm{M}$ & $\begin{array}{l}\text { arthritis (Glasson et al., 2005; Song et al., 2007; } \\
\text { Stanton et al., 2005) }\end{array}$ \\
\hline \multicolumn{4}{|l|}{6} \\
\hline 7 & ADAMTS-7B & COMP, $\alpha 2 M$ & $\begin{array}{l}\text { arthritis (Bai et al., 2009; Liu et al., 2006a, b; Luan } \\
\text { et al., 2008) }\end{array}$ \\
\hline 8 & METH-2 & aggrecan & $\begin{array}{l}\text { anti-angiogenesis, brain malignancy (Dunn et al., } \\
\text { 2006) } \\
\text { atherosclerosis (Wagsater et al., 2008; Moriguchi- } \\
\text { Goto et al., 2009) }\end{array}$ \\
\hline 9 & KIAA1312 & aggrecan, versican & arthritis (Demircan et al., 2005) \\
\hline \multicolumn{4}{|l|}{10} \\
\hline 12 & & aggrecan, COMP, $\alpha 2 \mathrm{M}$ & arthritis (Liu ei al., 2006a, b; Luan et al., 2008) \\
\hline 13 & vWFCP & von Willebrand factor & $\begin{array}{l}\text { thrombotic thrombocytopenic purpura (Levy et al., } \\
\text { 2001; Hovinga et al., 2004; Moake, 2004; } \\
\text { Shenkman, 2006) }\end{array}$ \\
\hline 14 & & procollagen I, II N-propeptide & \\
\hline 15 & & aggrecan & \\
\hline 16 & & aggrecan & \\
\hline \multicolumn{4}{|l|}{17} \\
\hline 18 & & & anti-thrombosis/stroke (Li et al., 2009) \\
\hline 19 & & aggrecan & \\
\hline 20 & & & \\
\hline
\end{tabular}

atherosclerotic plaque and atherothrombotic disease (Wagsater et al., 2008; Moriguchi-Goto et al., 2009).

\section{AGGRECANASES}

The proteoglycan aggrecan forms a major component of cartilage and plays a key role in protecting collagen from degradation (Pratta et al., 2003b). By interacting with hyaluronan and link proteins, aggrecan forms large aggregated complexes which fill the ECM collagen meshwork. The aggrecan molecule contains multiple glycosaminoglycan (GAG) side chains, which allow it to swell against the type II collagen scaffold in the presence of water. This is what gives articular cartilage the ability to resist compressive forces during joint loading (Roughley, 2001).

Aggrecan degradation is one of the key events underlying the pathogenesis of arthritis (Caterson et al., 2000; Sandy, 2003; Bondeson et al., 2008). ADAMTS-1, -4, -5, 8, and -15 
belong to a subgroup of ADAMTSs whose members can cleave aggrecan. ADAMTS-9, -16 , and -18 can also cleave aggrecan in vitro, although they do not belong to the subgroup (Somerville et al., 2003; Fosang et al., 2008). However, the expression and/or aggrecanase degrading activity of ADAMTS-1, $-8,-9,-15,-16$, and -18 are quite low, leaving ADAMTS- 4 and -5 as the two major functional aggrecanases (Fosang and Little, 2008; Tortorella and Malfait, 2008). ADAMTS-4, which is the best characterized aggrecanase, is able to bind to the ECM protein fibronectin, via its Cterminal spacer domain (Hashimoto et al., 2004) (Fig. 1). Cterminal proteolytic processing of full-length ADAMTS-4 $(74 \mathrm{kDa})$ breaks the attachment of the enzyme from ECM fibronectin, resulting in the release of processed isoforms (60 kDa and $50 \mathrm{kDa}$ ) (Flannery et al., 2002; Gao et al., 2002; Hashimoto et al., 2004; Kashiwagi et al., 2004). Furthermore, the $74 \mathrm{kDa}$ full-length ADAMTS-4 cleaves aggrecan at $\mathrm{Glu}^{1480}$-Gly $\mathrm{y}^{1481}$, while the processed isoforms cleave at $\mathrm{Glu}^{373}$-Ala ${ }^{374}$ (Gao et al., 2002; Kashiwagi et al., 2004). The aggrecanase activity of ADAMTS-4 depends specifically on its binding to the GAG chains of aggrecan, as evidenced by the presence of GAG binding sites in the C-terminal cysteinerich and/or spacer domains of ADAMTS-4 (Flannery et al., 2002). Interestingly, the interaction of fibronectin with ADAMTS-4 seems to inhibit its aggrecanase activity (Hashimoto et al., 2004). This suggests that fibronectin may compete with aggrecan for ADAMTS-4 binding, since both molecules seem to associate with the C-terminal spacer region of ADAMTS-4 (Flannery et al., 2002; Hashimoto et al., 2004). However, the GAG side chains of aggrecan can also bind to ADAMTS-4 via its TS repeat and such binding is critical for aggrecanase activity (Tortorella et al., 2000b; Kashiwagi et al., 2004).

Cleavage of aggrecan by ADAMTS- 4 and -5 occurs at the $\mathrm{Glu}^{373}$-Ala ${ }^{374}$ bond, as well as at four other sites. In vitro studies have demonstrated that cleavage at these four sites is actually more efficient than cleavage at the $\mathrm{Glu}^{373}-\mathrm{Ala}^{374}$ bond (Sugimoto et al., 1999; Tortorella et al., 2000b). However, cleavage at the $\mathrm{Glu}^{373}-\mathrm{Ala}^{374}$ bond is likely more important in the pathogenesis of osteoarthritis and inflammatory arthritis since a loss of integrity at this bond results in the loss of an entire aggrecan molecule, which is highly detrimental to cartilage integrity and function (Little et al., 2007). Indeed, cleavage of aggrecan at the $\mathrm{Glu}^{373}-\mathrm{Ala}^{374}$ bond is reported as a reliable marker for arthritis activity (Westling et al., 2002; Gendron et al., 2007) and fragments generated from this specific cleavage (characterized by the specific $\mathrm{N}$-terminus ARGSVIL epitope) have been identified in the synovial fluid of patients with OA (Sandy et al., 1992). Additionally, genetically modified mice with a $\mathrm{Glu}^{373}-\mathrm{Ala}^{374}$ bond that is resistant to cleavage, are characterized by diminished aggrecan loss and cartilage erosion in models of OA and inflammatory arthritis (Little et al., 2007). Interestingly, in ADAMTS-5 knockout mice, aggrecanolysis still occurs at sites other than the $\mathrm{Glu}^{373}$-Ala ${ }^{374}$ site, suggesting that
ADAMTS-4 or some other aggrecanase may be responsible (East et al., 2007). Thus, different aggrecanases may have differential preferences for separate regions of aggrecan.

Aggrecan fragments generated by ADAMTS-4 and -5mediated cleavage have been found in bovine articular cartilage explants treated with interleukin (IL)-1 and TNF- $\alpha$ (Tortorella et al., 2001). Treatment with either IL-1 or retinoic acid can also induce the release of such fragments. These fragments are actually present in normal articular cartilage and appear to accumulate with age (Lark et al., 1997; Yasumoto et al., 2003). Damaged cartilage also exhibits high levels of these fragments, as does cartilage that has been exposed to ADAMTS-4 or -5 (Lark et al., 1997; Sandy and Verscharen, 2001; Chockalingam et al., 2004).

Although ADAMTS-4 has been shown to effectively cleave aggrecan in vitro, ADAMTS-4 null mice are not protected from aggrecan loss. The same is true for ADAMTS-1 null mice. However, ADAMTS-5 knockout mice are protected from synovitis and joint destruction and thus ADAMTS- 5 is now thought to be the primary mediator of cartilage destruction in arthritis, at least in mice (Glasson et al., 2005; Stanton et al., 2005). This is supported by the observation that IL-1 $\alpha$ strongly stimulates the expression of ADAMTS-5, but not ADAMTS-4 in mice (Stanton et al., 2005).

Although ADAMTS-5 (and not ADAMTS-4) may play a major role in the development of arthritis in murine models, studies involving human tissue seem to suggest the opposite -that ADAMTS-4, (and not ADAMTS-5) is the major molecular player in human arthritis. For example, genetic variation in human ADAMTS- 5 does not seem to affect OA susceptibility (Rodriguez-Lopez et al., 2008). Furthermore, treatment with oncostatin M and either IL-1 $\beta$ or TNF- $\alpha$ in human chondrocytes or cartilage explants, leads to a marked induction of ADAMTS-4 with a lesser upregulation of ADAMTS-5 (Song et al., 2007). This process seems to be mediated by Ras signaling (Ahmad et al., 2009). Additionally, some data demonstrate that only ADAMTS-4 levels are increased in OA cartilage (Malfait et al., 2002; Roach et al., 2005; Naito et al., 2007). However, treatment of explanted human tissue with IL-1 $1 \alpha$ suggests that both ADAMTS-4 and -5 are important in human disease (Song et al., 2007). Both ADAMTS- 4 and -5 are highly expressed in human OA cartilage and both molecules seem to contribute to aggrecan loss in both normal and OA cartilage (Bau et al., 2002; Plaas et al., 2007; Song et al., 2007). Thus, while ADAMTS-5 (and not ADAMTS-4) is important in mice, it is ADAMTS-4 or perhaps both ADAMTS- 4 and -5 that play a key role in human arthritis.

ADAMTS-4 is also induced by a variety of other endogenously occurring molecules, which are of great interest, since they could represent novel targets for the development of therapeutics. These molecules include IL-1, TNF- $\alpha$, oncostatin M (OSM) and TGF- $\beta$, which have all been shown to upregulate ADAMTS-4 expression in cultured cartilage explants (Tortorella et al., 2001; Bau et al., 2002; Yamanishi 
et al., 2002; Pratta et al., 2003a). Interestingly, ADAMTS-5 expression is not induced by these factors. In a human chondrocyte line, the combination of IL-1 $\alpha$ and OSM upregulated ADAMTS-4, while ADAMTS- 5 was upregulated by IL- $1 \alpha$ only. This suggests that ADAMTS- 4 and ADAMTS- 5 may be differentially regulated by extracellular signaling. When taken in combination, these data seem to suggest that ADAMTS- 5 is constitutively expressed while ADAMTS- 4 is inducible (Vankemmelbeke et al., 2001; Bondeson et al., 2006; Fosang et al., 2008). In line with this reasoning, ADAMTS-4 expression in human synoviocytes is significantly inhibited by the clinically-available TNF- $\alpha$-blocker eternercept as well as by anti-IL- $1 \beta$ blocking antibodies, while ADAMTS- 5 is not affected (Bondeson et al., 2006).

The activities of ADAMTS- 4 and -5 are also likely modulated by other endogenous factors. PACE-4, which is secreted by human $O A$ chondrocytes, is a proprotein convertase that activates ADAMTS- 4 and -5 (Malfait et al., 2008). PACE- 4 is not produced by healthy articular cartilage.

Another endogenous factor that may modulate ADAMTS- 5 activity is syndecan-4, which belongs to the syndecan family of transmembrane heparan sulfate proteoglycans. Syndecans are known to interact with a variety of ECM molecules, growth factors, and cytokines (Tkachenko et al., 2005). It is thought that syndecan-4 activates ADAMTS- 5 through direct protein-protein interactions as well as by regulating the synthesis of MMP-3 via modulation of mitogen-activated protein kinase (MAPK) signaling (Echtermeyer et al., 2009). Syndecan-4 knockout mice exhibit decreased MMP-3 expression and blocking MMP-3 activity has been shown to reduce aggrecanase activity, although the molecular mechanism by which MMP-3 inhibits ADAMTS- 5 remains unknown. Of note, syndecan-4 knockout mice are protected from cartilage damage in a surgically induced model of osteoarthritis, highlighting the potential clinical relevance of both syndecan- 4 and ADAMTS- 5 to the pathogenesis of osteoarthritis.

In addition to osteoarthritis, the cleavage of aggrecanase by ADAMTS- 4 and/or- 5 may also play a role in the pathogenesis of Lyme arthritis, which is a manifestation of Lyme disease. Human chondrocytes infected with Borrelia burgdorferi, the causative agent of Lyme disease, show highly induced levels of ADAMTS-4, but not ADAMTS-5 (Behera et al., 2006). Active ADAMTS-4 levels are also increased in synovial fluid taken from patients with active Lyme arthritis. This suggests that the cleavage of aggrecan may be a precipitating factor in the pathogenesis of arthritis as it occurs in multiple different settings.

ADAMTS- 4 and -5 can have other functions as well. Both ADAMTS-4 and -5 are known to cleave human biglycan (Rees et al., 2000; Malemud, 2006; Gendron et al., 2007). Biglycan interacts with type VI collagen and plays a role in establishing the type VI collagen network (Wiberg et al., 2001, 2002). Biglycan degradation products are present in the ECM of articular cartilage from OA and RA patients (Melching et al.,
2006). However, it is still unclear whether this observation carries any functional significance.

\section{Aggrecanase Inhibitors}

With an advancing understanding of how aggrecanases mediate arthritis pathogenesis, recent attention has been turned to the conception of therapeutic strategies against disease progression. The goal of identifying and developing clinically effective inhibitors of ADAMTS- 4 and -5 seems promising, especially since suppression of ADAMTS-4 and -5 expression using siRNA leads to decreased aggrecan catabolism (Song et al., 2007) and deletion of these two genes provides significant protection against $O A$ in animal models (Glasson et al., 2005; llic et al., 2007; Majumdar et al., 2007). One example is the intra-articular injection of hyaluronan (HA), which is already in widespread clinical use and has been suggested to have a disease-modifying effect in $\mathrm{OA}$. Until recently, the mechanism of HA efficacy was unknown but a recent study revealed that HA suppresses aggrecan degradation by downregulating IL-1 $\alpha$-induced ADAMTS-4 expression by modulating CD44 and ICAM1 signaling pathways in osteoarthritic chondrocytes (Yatabe et al., 2009). Thus, HA is an example of how the inhibition of the aggrecanases may represent a clinically successful strategy in the treatment of $O A$.

A number of compounds are being investigated for their potential to inhibit the aggrecanases. A synthetic compound known as calcium pentosan polysulfate (CaPPS) has been shown to interact with the spacer domain of ADAMTS-4 and the cysteine-rich domain of ADAMTS-5 (Takizawa et al., 2008; Troeberg et al., 2008). CaPPS also increases the cartilage levels of TIMP-3, which is the only TIMP (tissue inhibitor of metalloproteinases) capable of inhibiting ADAMTS- 4 and -5 . Furthermore, CaPPS increases the affinity of TIMP-3 by more than 100-fold (Troeberg et al., 2008). Nobiletin is a citrus polymethoxy flavone that can inhibit IL-1 $\beta$-mediated ADAMTS-4 and -5 expression (Imada et al., 2008). It is also effective in suppressing ADAMTS-4 and -5 expression and aggrecan degradation in a collageninduced arthritis mouse model. $\mathrm{N}-3$ polyunsaturated fatty acids have been shown to downregulate the mRNA of ADAMTS-4 (Curtis et al., 2002). Additionally, the C-terminal portion of fibronectin has also been reported to inhibit ADAMTS-4 (Kramerova et al., 2000; Hashimoto et al., 2004). Thus, the development of clinically effective inhibitors of ADAMTS- 4 and -5 remains an area of active research. Also, although some compounds seem to inhibit one aggrecanase over another, it seems that inhibition of both ADAMTS- 4 and -5 will be necessary to achieve an optimal therapeutic effect (Bursavich et al., 2007a, b).

Some drugs that are already in clinical use have been evaluated for their possible anti-aggrecanase effects. Glucosamine is a dietary supplement with controversial effects on pain and joint function in OA (Clegg et al., 2006; 
Herrero-Beaumont et al., 2007; Reginster, 2007; Vlad et al., 2007). As such, it is not currently recognized as a disease modifying agent by regulatory agencies (Zhang et al., 2007). Nonetheless, experiments involving rat chondrosarcoma cells and bovine cartilage explants have demonstrated that glucosamine can inhibit aggrecanase activity in vitro (Sandy et al., 1998). It has also been demonstrated that glucosamine can inhibit IL-1-induced ADAMTS-4 and -5 expression in chondrocytes (Chan et al., 2006). Another compound, diacerhein, is effective in treating hip OA (Rintelen et al., 2006). Diacerhein has been shown to inhibit IL-1-induced ADAMTS-4 expression in bovine cartilage explants, by modulating NF-KB, AP-1, and JNK signaling.

Endogenous inhibitors of ADAMTS- 4 and -5 have also been studied. Although TIMPs are broadly effective inhibitors of the MMP family (Baker et al., 2002), ADAMTS-4 and ADAMTS- 5 are inhibited by only TIMP-3, but not TIMP-1, -2, -4 , or any other TIMP (Arner et al., 1999; Kashiwagi et al., 2001; Hashimoto et al., 2003; Wayne et al., 2007). TIMP-3 knockout mice exhibit increased aggrecan loss with mild cartilage degradation (Mahmoodi et al., 2005; Sahebjam et al., 2007).

Like the TIMP-3, the heparan-binding growth factor fibroblast growth factor 2 (FGF-2) is another potential endogenous aggrecanase inhibitor. FGF-2 is bound to the $\mathrm{ECM}$ and released following mechanical injury. FGF-2 knockout mice exhibit accelerated OA, both spontaneously and following surgical induction. Additionally, surgically induced OA in FGF-2 knockout mice is suppressed by the administration of recombinant FGF-2. FGF-2 knockout mice also exhibit increased expression of ADAMTS- 5 mRNA (Chia et al., 2009). This confirms previous studies involving primary human chondrocytes demonstrating that FGF-2 prevents aggrecan degradation and inhibits IL- $1 \alpha$-induced ADAMTS-4 and -5 expression, suggesting that FGF-2 may protect against OA by suppressing these two ADAMTSs (Sawaji et al., 2008).

Another endogenous inhibitor of ADAMTS- 4 and -5 is $\alpha 2-$ Macroglobulin ( $\alpha 2 M)$, which is a general endoprotease inhibitor that is found in serum and joint fluid and is active against most endoproteases (Hadler et al., 1981; Chu et al., 1994). Each a2M molecule contains a stretch of amino acids, known as the "bait region". When a protease cleaves the bait region, a2M undergoes a conformational change, trapping the protease inside, and sequestering it from interaction with other substrates. Both ADAMTS-4 and -5 are able to cleave the bait region of $\alpha 2 \mathrm{M}$ and are thus inhibited by $\alpha 2 \mathrm{M}$ (Tortorella et al., 2004). However, attempts to identify a2M in the synovial fluid of OA patients have proven unsuccessful.

\section{ADAMTS-7 AND -12}

ADAMTS-7 and ADAMTS-12 are two recently discovered members of the ADAMTS family, and form their own subgroup with unique properties. There is emerging evidence to suggest that both ADAMTS-7 and ADAMTS-12 may play key roles in the pathogenesis of arthritis (Liu, 2009). One study has found that ADAMTS-7 is significantly upregulated in arthritic cartilage and synovium (Liu et al., 2006a). And while ADAMTS-7 and 12 are both significantly upregulated in the cartilage of RA patients, only ADAMTS- 12 is significantly upregulated in OA patients (Liu et al., 2006a, b).

As is in the case of ADAMTS-4 and -5 , inflammatory cytokines such as tumor necrosis factor (TNF) and IL-1 $\beta$ have been shown to induce the expression of a number of MMPs (Bevitt et al., 2003; Voros et al., 2003; Cross et al., 2006). Real-time PCR analysis of cultured human cartilage explants show that both TNF and IL-1 $\beta$ strongly induce ADAMTS-7 and -12 expression (Luan et al., 2008). Interestingly, cytokinebased induction of ADAMTS-12 does not occur in human fetal fibroblasts (Cal et al., 2001). This suggests that ADAMTS induction mediated by inflammatory cytokines may not occur in all tissue types.

\section{COMP}

Since arthritis is characterized by the proteolytic degradation of extracellular matrix proteins, much attention has been turned to identifying the mechanisms underlying the degradation of specific ECM components, such as aggrecan and collagen II. The $524 \mathrm{kDa}$ disulfide-bonded multi-domain glycoprotein, cartilage oligomeric matrix protein (COMP), is a component of cartilage ECM (Hedbom et al., 1992). Human COMP gene mutations have been linked to the development of autosomal-dominant forms of short-limb dwarfism, such as pseudoachondroplasia and multiple epiphyseal dysplasia (Briggs et al., 1995; Hecht et al., 1995; Cohn et al., 1996; Briggs et al., 1998). The function of COMP is not entirely understood, although it appears to mediate chondrocyte attachment via an integrin receptor (DiCesare et al., 1994; Chen et al., 2005). COMP may also function to stabilize cartilage ECM via specific interactions with matrix components such as collagen type II and IX, aggrecan, and fibronectin (Mansson et al., 1995; Rosenberg et al., 1998; Di Cesare et al., 2002; Chan et al., 2007).

The degradation of COMP may play a key role in the pathogenesis of arthritis. COMP fragments have been detected in the cartilage, synovial fluid, and serum of patients with post-traumatic knee injuries, primary osteoarthritis and rheumatoid arthritis (Saxne and Heinegard, 1992; Neidhart et al., 1997). Several recent studies have also suggested that the level of COMP in joint fluid and/or serum may be useful as a marker in assessing disease severity in a clinical setting (Mansson et al., 1995; Neidhart, 1996; Lohmander et al., 1999; Kraus et al., 2002; Misumi et al., 2002). Thus, the identification of enzymes responsible for the degradation of COMP is of potential significance-both to elucidate the biological mechanisms underlying the disease process, as 
well as to develop novel approaches in diagnosis and therapy.

Several MMPs can digest COMP in vitro, including MMP-1, $-3,-9,-13,-19$, and -20 (Ganu et al., 1998; Stracke et al., 2000). Interestingly, ADAMTS-4 has also been reported to cleave COMP in vitro (Dickinson et al., 2003). However, the exact role of MMPs in COMP degradation has yet to be confirmed by in vivo animal studies.

The ability of ADAMTS-7 and -12 to bind COMP was first established in our lab. We used a yeast-two-hybrid functional genomic screen to identify both ADAMTS-7 and -12 as COMP-binding metalloproteinases, a result that was later confirmed by co-immunoprecipitation studies demonstrating that this interaction occurs in vivo (Liu et al., 2006a, b). Using ADAMTS- 7 and -12 deletion mutants, we then discovered that four C-terminal thrombospondin type-1 repeats are conserved in both enzymes and are required for COMP cleavage, an event that requires binding to the EGF-like domain of COMP. These findings are unsurprising since Cterminal domains of metalloproteinases are often important for determining substrate specificity (Martel-Pelletier et al., 2001).

Bone, cartilage, synovium, tendon and ligament all contain COMP (Hedbom et al., 1992; DiCesare et al., 1994), and each of these tissues also expresses ADAMTS-7. ADAMTS-7 is also detectable in meniscus, skeletal muscle and fat (Liu et al., 2006a). ADAMTS-12 can be detected in cartilage, synovium, tendon, skeletal muscle and fat, as evidenced by real-time PCR data (Cal et al., 2001; Liu et al., 2006b). If ADAMTS-7 and -12 can both interact with COMP, we would expect these molecules to be co-localized, not only in the same tissues, but also within the same sub-cellular location. Immunostaining analysis demonstrates that this is the caseADAMTS-7 and -12 are co-localized with COMP both in the cytoplasm and on the surface of human chondrocytes (Liu et al., 2006a, b). These studies also suggest that COMP may mediate the interaction between ADAMTS-7 and -12 and the chondrocyte membrane. In vivo immunohistochemistry assays performed on embryonic murine limbs demonstrate significant overlap between ADAMTS-7, -12, and COMP expression patterns.

Subsequent studies involving recombinant enzyme, conditioned medium, and purified protein, have demonstrated that both ADAMTS-7 and -12 can digest COMP in vitro (Liu et al., 2006a, b). An analysis of COMP fragments taken from in vitro assays suggests that ADAMTS-7 may cleave COMP at multiple sites (Neidhart et al., 1997). Importantly, COMP fragments taken from the cartilage explants of osteoarthritis patients are of similar size to those found with in vitro studies (110 kDa) (Luan et al., 2008). This highlights the possible role that the digestion of COMP by ADAMTS-7 and -12 may play in degenerative joint disease.

Since inflammatory cytokines TNF- $\alpha$ and IL- $1 \beta$ have been shown to induce the expression of ADAMTS-7 and -12, these cytokines would also be expected to induce COMP degradation by upregulating these enzymes. Indeed, abundant $110 \mathrm{kDa}$ COMP fragments are seen in cartilage explants treated with both cytokines, and these fragments are completely eliminated in the presence of anti-ADAMTS-7 and ADAMTS-12 antibodies (Luan et al., 2008). This provides strong evidence to suggest that ADAMTS-7 and -12 serve to mediate the link between inflammatory cytokines and ECM degradation. Experiments involving siRNA silencing of ADAMTS-7 and -12 in human chondrocytes confirms these results (Luan et al., 2008). The next logical step would be to validate these findings in vivo by generating ADAMTS-7 or12-null mice in an arthritis model. Interestingly, findings demonstrating the role of ADAMTS- 5 in aggrecan degradation using osteoarthritis and inflammatory arthritis mouse models are based on this type of approach (Glasson et al., 2005).

Like ADAMTS- 4 and -5 , ADAMTS- 7 and -12 are also affected by the action of $\alpha 2 \mathrm{M}$. Both ADAMTS- 7 and -12 are able to cleave $\alpha 2 \mathrm{M}$ in its bait region, and $\alpha 2 \mathrm{M}$ is able to inhibit the COMP degrading activities of ADAMTS-7 and -12 (Luan et al., 2008). The ability of $\alpha 2 M$ to interact with four ADAMTSs that have been implicated in arthritis, suggests that future study of this endogenous protease inhibitor may help us to better understand arthritis pathogenesis.

\section{GEP}

A recent study has found that COMP associates with granulin-epithelin precursor (GEP), a growth factor that is highly expressed in chondrocytes and is strongly upregulated in the synovium of both OA and RA patients (Xu et al., 2007). GEP is an $80 \mathrm{kDa}$ secreted glycoprotein that contains seven and a half repeats of a cysteine-rich motif (Wright et al., 1989; Anakwe and Gerton, 1990; Zhou et al., 1993; Ong and Bateman, 2003). It acts as an autocrine growth factor, and undergoes proteolytic processing to produce $\sim 6 \mathrm{kDa}$ repeating units known as granulins, which retain at least some of the biologic activity of GEP (Davidson et al., 2004). These peptides are active in cell growth assays and may be mediators of inflammation (Zanocco-Marani et al., 1999; Lu and Serrero, 2000).

The finding that COMP associates with both ADAMTS-7 and GEP suggests that these three molecules may form a protein-protein interaction network, whereby co-regulation of all three molecules is intertwined. We performed yeast-2hybrid and co-immunoprecipitation assays demonstrating that ADAMTS-7 does indeed associate with GEP and that the four C-terminal TS repeats of ADAMTS-7 are required for this interaction (Bai et al., 2009).

GEP exhibits a potent anti-protease activity-it inhibits TNF-induced protease and GEP-derived granulin inhibits the protease thrombin (Hong and Kang, 1999; Zhu et al., 2002). Unpublished data from our lab demonstrate that GEP specifically inhibits COMP degradation by ADAMTS-7 
and -12 . When GEP and ADAMTS-7 are co-expressed in a COMP-stable cell line, ADAMTS-7-mediated COMP degradation is significantly inhibited (Guo et al., unpublished data). In addition, data from an in vitro digestion assay show that GEP prevents ADAMTS-12 from degrading COMP (Guo et al., unpublished data). Further data show that ADAMTS-7 can also be categorized as a GEP convertase, since it is involved in the proteolytic processing of GEP with the liberation of small fragments (Bai et al., 2009).

The available data suggest that GEP inhibits the action of ADAMTS-7 via two distinct mechanisms. First, GEP inhibits the induction of ADAMTS-7 by inflammatory cytokines such as TNF- $\alpha$. Second, it disrupts the association between ADAMTS-7 and COMP via a direct protein-to-protein interaction (Liu, 2009). Thus, ADAMTS-7 and -12 metalloproteinases, COMP extracellular matrix protein, GEP growth factor, and TNF inflammatory cytokine all act in concert to form a key interaction and interplay network in the pathogenesis of arthritis (Fig. 2).

\section{OTHER ADAMTSs}

Like ADAMTS-4 and -5 , ADAMTS-9 is also known to have aggrecan degrading activity and is highly activated by both TNF- $\alpha$ and IL- $1 \beta$ in both chondrosarcoma cells and human chondrocytes (Demircan et al., 2005). Cloning of the ADAMTS-9 promoter reveals putative binding sites for Nuclear Factor of Activated T cells (NFAT), which is commonly found in ADAMTS-4 and -5 promoters (Yaykasli et al., 2009). 11R-VIVIT, a peptide that inhibits NFAT activation, is able to block the induction of ADAMTS- 9 by IL-1 $\beta$. Since ADAMTS-4 and -5 promoters also contain NFAT binding sites, this finding may aid the development of aggrecanases inhibitors that specifically target NFAT activation.

Another recent study investigated the possible role of various ADAMTSs by analyzing SNPs in 18 ADAMTS genes (Rodriguez-Lopez et al., 2009). ADAMTS-14 was specifically singled out, as a rare allele was overrepresented in women requiring joint replacement due to knee OA. ADAMTS-14 plays a role in procollagen I processing in vitro, although its function in vivo is still unknown (Colige et al., 2002).

\section{SUMMARY AND PERSPECTIVES}

Exploring the role of the ADAMTSs, particularly ADAMTS-4, $-5,-7$, and -12 , in arthritic diseases has been advanced significantly by recent discoveries (Fig. 2). Indeed, the finding that these molecules are able to interact with and modulate cartilage ECM components provides us with new potential to

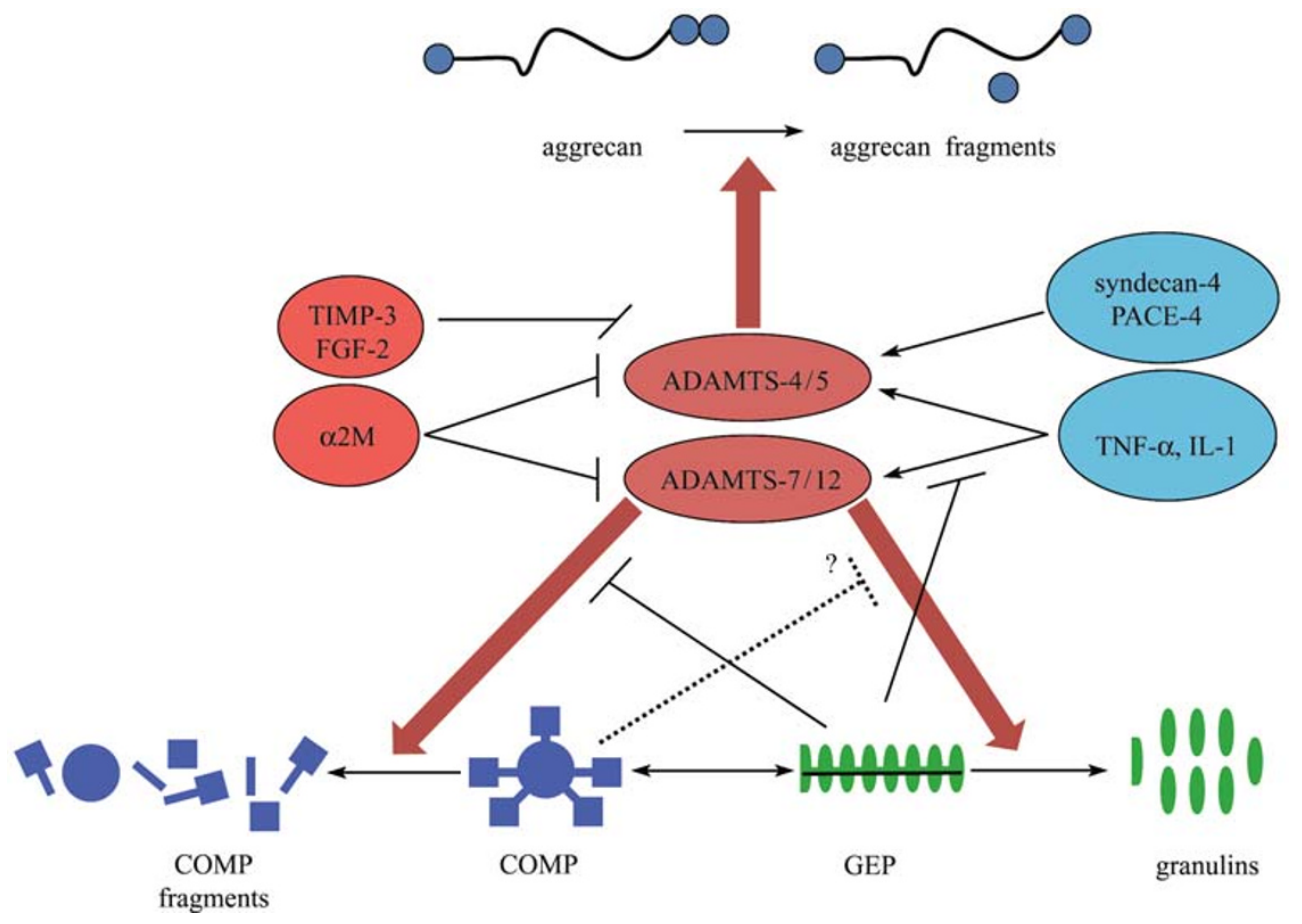

Figure 2. An interaction network in the degradation of extracellular matrix mediated by ADAMTS-4, $-\mathbf{5}, \mathbf{- 7}$, and -12 . ADAMTS-4 and -5-mediated proteolysis of aggrecan is positively modulated by TNF- $\alpha$, IL-1, syndecan- 4 and PACE-4, and inhibited by TIMP-3, FGF-2 and $\alpha 2$ M. ADAMTS-7 and -12-mediated proteolysis of COMP and GEP is stimulated by TNF- $\alpha$ and IL-1 and inhibited by $\alpha 2 \mathrm{M}$. Arrows indicate a stimulatory effect. Perpendicular lines indicate an inhibitory effect. A dotted line indicates that the relationship is based on unpublished data. Note that ADAMTS-4 also degrades COMP (Dickinson et al., 2003), and ADAMTS-12 also cleaves aggrecan (Llamazares et al., 2007). 
generate specific therapies. By targeting the ADAMTSs, these new therapies would address one of the fundamental processes behind arthritis pathogenesis, namely the destruction of cartilage ECM components. It is this destruction that underlies the loss of cartilage biology, integrity and ultimately functions. Thus, halting or even reversing this destruction could be one of the keys in achieving disease remission. This is the underlying principle behind the ongoing interest in both endogenous and exogenous ADAMTs inhibitors.

Although this review focuses on the role of ADAMTSs in the pathogenesis of arthritis, recent evidence has emerged to implicate these same molecules in a host of other biological and disease processes. Indeed, ADAMTS-4, $-5,-7$, and -12 could potentially play a key role in the pathogenesis of today's most common and costly diseases, including arthritis, atherosclerosis and cancer, thus highlighting the importance of future study. Learning the full relationship between the ADAMTSs, their inhibitors, and their binding partners, holds the promise of helping us to better understand the pathogenesis of, as well as develop effective therapies for arthritis as well as many other diseases.

\section{ACKNOWLEDGEMENTS}

C. J. Liu is grateful to his gifted collaborators who made the explorations in his laboratory possible. Studies in our laboratory were aided by NIH research grants AR050620, AR053210, and AG029388 and a grant from the Arthritis National Research Foundation.

\section{ABBREVIATIONS}

a2M, a2-Macroglobulin; ADAMTS, a disintegrin and metalloproteinase with thrombospondin motifs; CaPPS, calcium pentosan polysulfate; COMP, cartilage oligomeric matrix protein; ECM, extracellular matrix; FGF-2, fibroblast growth factor 2; GAG, glycosaminoglycan; GEP, granulin-epithelin precursor; HA, hyaluronan; IL, interleukin; MAPK, mitogen-activated protein kinase; MMP, matrix metalloproteinases; OA, osteoarthritis; OSM, oncostatin M; RA, rheumatoid arthritis; TIMP, tissue inhibitor of metalloproteinases; TNF, tumor necrosis factor; TS, thrombospondin type I-like

\section{REFERENCES}

Ahmad, R., Sylvester, J., Ahmad, M., and Zafarullah, M. (2009). Adaptor proteins and Ras synergistically regulate IL-1-induced ADAMTS-4 expression in human chondrocytes. J Immunol 182, 5081-5087.

Anakwe, O.O., and Gerton, G.L. (1990). Acrosome biogenesis begins during meiosis: evidence from the synthesis and distribution of an acrosomal glycoprotein, acrogranin, during guinea pig spermatogenesis. Biol Reprod 42, 317-328.

Apte, S.S. (2004). A disintegrin-like and metalloprotease (reprolysin type) with thrombospondin type 1 motifs: the ADAMTS family. Int $J$ Biochem Cell Biol 36, 981-985.

Apte, S.S. (2009). A disintegrin-like and metalloprotease (reprolysin-type) with hrombospondin type 1 motif (ADAMTS) superfamily-functions and mechanisms. J Biol Chem 284, 31493-31497

Arner, E.C., Pratta, M.A., Trzaskos, J.M., Decicco, C.P., and Tortorella, M.D. (1999). Generation and characterization of aggrecanase. A soluble, cartilage-derived aggrecan-degrading activity. J Biol Chem 274, 6594-6601.

Bai, X.H., Wang, D.W., Kong, L., Zhang, Y., Luan, Y., Kobayashi, T., Kronenberg, H.M., Yu, X.P., and Liu, C.J. (2009). ADAMTS-7, a Direct Target of PTHrP, Adversely Regulates Endochondral Bone Growth via Associating with and Inactivating GEP Growth Factor. Mol Cell Biol. In press.

Baker, A.H., Edwards, D.R., and Murphy, G. (2002). Metalloproteinase inhibitors: biological actions and therapeutic opportunities. $J$ Cell Sci 115, 3719-3727.

Barreda, D.R., Hanington, P.C., Walsh, C.K., Wong, P., and Belosevic, M. (2004). Differentially expressed genes that encode potential markers of goldfish macrophage development in vitro. Dev Comp Immunol 28, 727-746.

Basile, D.P., Fredrich, K., Chelladurai, B., Leonard, E.C., and Parrish, A.R. (2008). Renal ischemia reperfusion inhibits VEGF expression and induces ADAMTS-1, a novel VEGF inhibitor. Am J Physiol Renal Physiol 294, F928-936.

Bau, B., Gebhard, P.M., Haag, J., Knorr, T., Bartnik, E., and Aigner, T. (2002). Relative messenger RNA expression profiling of collagenases and aggrecanases in human articular chondrocytes in vivo and in vitro. Arthritis Rheum 46, 2648-2657.

Behera, A.K., Hildebrand, E., Szafranski, J., Hung, H.H., Grodzinsky, A.J., Lafyatis, R., Koch, A.E., Kalish, R., Perides, G., Steere, A.C., et al. (2006). Role of aggrecanase 1 in Lyme arthritis. Arthritis Rheum 54, 3319-3329.

Bergeron, F., Leduc, R., and Day, R. (2000). Subtilase-like pro-protein convertases: from molecular specificity to therapeutic applications. $\mathrm{J}$ Mol Endocrinol 24, 1-22.

Bevitt, D.J., Mohamed, J., Catterall, J.B., Li, Z., Arris, C.E., Hiscott, P., Sheridan, C., Langton, K.P., Barker, M.D., Clarke, M.P., et al. (2003). Expression of ADAMTS metalloproteinases in the retinal pigment epithelium derived cell line ARPE-19: transcriptional regulation by TNFalpha. Biochim Biophys Acta 1626, 83-91.

Bondeson, J., Wainwright, S., Hughes, C., and Caterson, B. (2008). The regulation of the ADAMTS4 and ADAMTS5 aggrecanases in osteoarthritis: a review. Clin Exp Rheumatol 26, 139-145.

Bondeson, J., Wainwright, S.D., Lauder, S., Amos, N., and Hughes, C.E. (2006). The role of synovial macrophages and macrophageproduced cytokines in driving aggrecanases, matrix metalloproteinases, and other destructive and inflammatory responses in osteoarthritis. Arthritis Res Ther 8, R187.

Briggs, M.D., Hoffman, S.M., King, L.M., Olsen, A.S., Mohrenweiser, H., Leroy, J.G., Mortier, G.R., Rimoin, D.L., Lachman, R.S., Gaines, E.S., et al. (1995). Pseudoachondroplasia and multiple epiphyseal dysplasia due to mutations in the cartilage oligomeric matrix protein gene. Nat Genet 10, 330-336.

Briggs, M.D., Mortier, G.R., Cole, W.G., King, L.M., Golik, S.S., Bonaventure, J., Nuytinck, L., De Paepe, A., Leroy, J.G., Biesecker, L., et al. (1998). Diverse mutations in the gene for cartilage oligomeric matrix protein in the pseudoachondroplasia-multiple epiphyseal dysplasia disease spectrum. Am J Hum Genet 62, 311-319. 
Brown, H.M., Dunning, K.R., Robker, R.L., Pritchard, M., and Russell, D.L. (2006). Requirement for ADAMTS-1 in extracellular matrix remodeling during ovarian folliculogenesis and lymphangiogenesis. Dev Biol 300, 699-709.

Burrage, P.S., Mix, K.S., and Brinckerhoff, C.E. (2006). Matrix metalloproteinases: role in arthritis. Front Biosci 11, 529-543.

Bursavich, M.G., Gilbert, A.M., Lombardi, S., Georgiadis, K.E., Reifenberg, E., Flannery, C.R., and Morris, E.A. (2007a). 5'Phenyl-3'H-spiro[indoline-3,2'-[1,3,4]thiadiazol]-2-one inhibitors of ADAMTS-5 (aggrecanase-2). Bioorg Med Chem Lett 17, 5630-5633.

Bursavich, M.G., Gilbert, A.M., Lombardi, S., Georgiadis, K.E., Reifenberg, E., Flannery, C.R., and Morris, E.A. (2007b). Synthesis and evaluation of aryl thioxothiazolidinone inhibitors of ADAMTS-5 (Aggrecanase-2). Bioorg Med Chem Lett 17, 1185-1188.

Cal, S., Arguelles, J.M., Fernandez, P.L., and Lopez-Otin, C. (2001). Identification, characterization, and intracellular processing of ADAM-TS12, a novel human disintegrin with a complex structural organization involving multiple thrombospondin-1 repeats. J Biol Chem 276, 17932-17940.

Caterson, B., Flannery, C.R., Hughes, C.E., and Little, C.B. (2000). Mechanisms involved in cartilage proteoglycan catabolism. Matrix Biol 19, 333-344.

Chan, I., Liu, L., Hamada, T., Sethuraman, G., and McGrath, J.A. (2007). The molecular basis of lipoid proteinosis: mutations in extracellular matrix protein 1. Exp Dermatol 16, 881-890.

Chan, P.S., Caron, J.P., and Orth, M.W. (2006). Short-term gene expression changes in cartilage explants stimulated with interleukin beta plus glucosamine and chondroitin sulfate. J Rheumatol 33, 1329-1340.

Chen, F.H., Thomas, A.O., Hecht, J.T., Goldring, M.B., and Lawler, J. (2005). Cartilage oligomeric matrix protein/thrombospondin 5 supports chondrocyte attachment through interaction with integrins. J Biol Chem 280, 32655-32661.

Chia, S.L., Sawaji, Y., Burleigh, A., McLean, C., Inglis, J., Saklatvala, J., and Vincent, T. (2009). Fibroblast growth factor 2 is an intrinsic chondroprotective agent that suppresses ADAMTS- 5 and delays cartilage degradation in murine osteoarthritis. Arthritis Rheum 60, 2019-2027.

Chockalingam, P.S., Zeng, W., Morris, E.A., and Flannery, C.R. (2004). Release of hyaluronan and hyaladherins (aggrecan G1 domain and link proteins) from articular cartilage exposed to ADAMTS-4 (aggrecanase 1) or ADAMTS-5 (aggrecanase 2). Arthritis Rheum 50, 2839-2848.

Chu, C.T., Howard, G.C., Misra, U.K., and Pizzo, S.V. (1994). Alpha 2macroglobulin: a sensor for proteolysis. Ann N Y Acad Sci 737, 291-307.

Clark, I.M., and Parker, A.E. (2003). Metalloproteinases: their role in arthritis and potential as therapeutic targets. Expert Opin Ther Targets 7, 19-34.

Clegg, D.O., Reda, D.J., Harris, C.L., Klein, M.A., O'Dell, J.R., Hooper, M.M., Bradley, J.D., Bingham, C.O., 3rd, Weisman, M.H., Jackson, C.G., et al. (2006). Glucosamine, chondroitin sulfate, and the two in combination for painful knee osteoarthritis. N Engl J Med 354, 795-808.

Cohn, D.H., Briggs, M.D., King, L.M., Rimoin, D.L., Wilcox, W.R., Lachman, R.S., and Knowlton, R.G. (1996). Mutations in the cartilage oligomeric matrix protein (COMP) gene in pseudoachondroplasia and multiple epiphyseal dysplasia. Ann N Y Acad Sci
785, 188-194.

Colige, A., Nuytinck, L., Hausser, I., van Essen, A.J., Thiry, M., Herens, C., Ades, L.C., Malfait, F., Paepe, A.D., Franck, P., et al. (2004). Novel types of mutation responsible for the dermatosparactic type of Ehlers-Danlos syndrome (Type VIIC) and common polymorphisms in the ADAMTS2 gene. J Invest Dermatol 123, 656-663.

Colige, A., Sieron, A.L., Li, S.W., Schwarze, U., Petty, E., Wertelecki, W., Wilcox, W., Krakow, D., Cohn, D.H., Reardon, W., et al. (1999). Human Ehlers-Danlos syndrome type VII C and bovine dermatosparaxis are caused by mutations in the procollagen I $\mathrm{N}$-proteinase gene. Am J Hum Genet 65, 308-317.

Colige, A., Vandenberghe, I., Thiry, M., Lambert, C.A., Van Beeumen, J., Li, S.W., Prockop, D.J., Lapiere, C.M., and Nusgens, B.V. (2002). Cloning and characterization of ADAMTS-14, a novel ADAMTS displaying high homology with ADAMTS-2 and ADAMTS-3. J Biol Chem 277, 5756-5766.

Corps, A.N., Jones, G.C., Harrall, R.L., Curry, V.A., Hazleman, B.L., and Riley, G.P. (2008). The regulation of aggrecanase ADAMTS-4 expression in human Achilles tendon and tendon-derived cells. Matrix Biol 27, 393-401.

Cross, A.K., Haddock, G., Stock, C.J., Allan, S., Surr, J., Bunning, R. A., Buttle, D.J., and Woodroofe, M.N. (2006). ADAMTS-1 and -4 are up-regulated following transient middle cerebral artery occlusion in the rat and their expression is modulated by TNF in cultured astrocytes. Brain Res 1088, 19-30.

Curtis, C.L., Rees, S.G., Little, C.B., Flannery, C.R., Hughes, C.E., Wilson, C., Dent, C.M., Otterness, I.G., Harwood, J.L., and Caterson, B. (2002). Pathologic indicators of degradation and inflammation in human osteoarthritic cartilage are abrogated by exposure to n-3 fatty acids. Arthritis Rheum 46, 1544-1553.

Davidson, B., Alejandro, E., Florenes, V.A., Goderstad, J.M., Risberg, B., Kristensen, G.B., Trope, C.G., and Kohn, E.C. (2004). Granulinepithelin precursor is a novel prognostic marker in epithelial ovarian carcinoma. Cancer 100, 2139-2147.

Demircan, K., Hirohata, S., Nishida, K., Hatipoglu, O.F., Oohashi, T., Yonezawa, T., Apte, S.S., and Ninomiya, Y. (2005). ADAMTS-9 is synergistically induced by interleukin-1beta and tumor necrosis factor alpha in OUMS-27 chondrosarcoma cells and in human chondrocytes. Arthritis Rheum 52, 1451-1460.

Di Cesare, P.E., Chen, F.S., Moergelin, M., Carlson, C.S., Leslie, M. P., Perris, R., and Fang, C. (2002). Matrix-matrix interaction of cartilage oligomeric matrix protein and fibronectin. Matrix Biol 21, 461-470.

DiCesare, P., Hauser, N., Lehman, D., Pasumarti, S., and Paulsson, M. (1994). Cartilage oligomeric matrix protein (COMP) is an abundant component of tendon. FEBS Lett 354, 237-240.

Dickinson, S.C., Vankemmelbeke, M.N., Buttle, D.J., Rosenberg, K., Heinegard, D., and Hollander, A.P. (2003). Cleavage of cartilage oligomeric matrix protein (thrombospondin-5) by matrix metalloproteinases and a disintegrin and metalloproteinase with thrombospondin motifs. Matrix Biol 22, 267-278.

Dunn, J.R., Reed, J.E., du Plessis, D.G., Shaw, E.J., Reeves, P., Gee, A.L., Warnke, P., and Walker, C. (2006). Expression of ADAMTS-8, a secreted protease with antiangiogenic properties, is downregulated in brain tumours. Br J Cancer 94, 1186-1193.

East, C.J., Stanton, H., Golub, S.B., Rogerson, F.M., and Fosang, A. J. (2007). ADAMTS-5 deficiency does not block aggrecanolysis at preferred cleavage sites in the chondroitin sulfate-rich region of 
aggrecan. J Biol Chem 282, 8632-8640.

Echtermeyer, F., Bertrand, J., Dreier, R., Meinecke, I., Neugebauer, K., Fuerst, M., Lee, Y.J., Song, Y.W., Herzog, C., Theilmeier, G., et al. (2009). Syndecan-4 regulates ADAMTS-5 activation and cartilage breakdown in osteoarthritis. Nat Med 15, 1072-1076.

Flannery, C.R., Zeng, W., Corcoran, C., Collins-Racie, L.A., Chockalingam, P.S., Hebert, T., Mackie, S.A., McDonagh, T., Crawford, T. K., Tomkinson, K.N., et al. (2002). Autocatalytic cleavage of ADAMTS-4 (Aggrecanase-1) reveals multiple glycosaminoglycanbinding sites. J Biol Chem 277, 42775-42780.

Fosang, A.J., and Little, C.B. (2008). Drug insight: aggrecanases as therapeutic targets for osteoarthritis. Nat Clin Pract Rheumatol 4, 420-427.

Fosang, A.J., Rogerson, F.M., East, C.J., and Stanton, H. (2008). ADAMTS-5: the story so far. Eur Cell Mater 15, 11-26.

Ganu, V., Goldberg, R., Peppard, J., Rediske, J., Melton, R., Hu, S.I., Wang, W., Duvander, C., and Heinegard, D. (1998). Inhibition of interleukin-1alpha-induced cartilage oligomeric matrix protein degradation in bovine articular cartilage by matrix metalloproteinase inhibitors: potential role for matrix metalloproteinases in the generation of cartilage oligomeric matrix protein fragments in arthritic synovial fluid. Arthritis Rheum 41, 2143-2151.

Gao, G., Plaas, A., Thompson, V.P., Jin, S., Zuo, F., and Sandy, J.D. (2004). ADAMTS4 (aggrecanase-1) activation on the cell surface involves C-terminal cleavage by glycosylphosphatidyl inositolanchored membrane type 4-matrix metalloproteinase and binding of the activated proteinase to chondroitin sulfate and heparan sulfate on syndecan-1. J Biol Chem 279, 10042-10051.

Gao, G., Westling, J., Thompson, V.P., Howell, T.D., Gottschall, P.E., and Sandy, J.D. (2002). Activation of the proteolytic activity of ADAMTS4 (aggrecanase-1) by C-terminal truncation. J Biol Chem 277, 11034-11041.

Gendron, C., Kashiwagi, M., Lim, N.H., Enghild, J.J., Thogersen, I.B., Hughes, C., Caterson, B., and Nagase, H. (2007). Proteolytic activities of human ADAMTS-5: comparative studies with ADAMTS-4. J Biol Chem 282, 18294-18306.

Glasson, S.S., Askew, R., Sheppard, B., Carito, B., Blanchet, T., Ma, H.L., Flannery, C.R., Peluso, D., Kanki, K., Yang, Z., et al. (2005). Deletion of active ADAMTS5 prevents cartilage degradation in a murine model of osteoarthritis. Nature 434, 644-648.

Hadler, N.M., Johnson, A.M., Spitznagel, J.K., and Quinet, R.J. (1981). Protease inhibitors in inflammatory synovial effusions. Ann Rheum Dis 40, 55-59.

Hashimoto, G., Shimoda, M., and Okada, Y. (2004). ADAMTS4 (aggrecanase-1) interaction with the C-terminal domain of fibronectin inhibits proteolysis of aggrecan. J Biol Chem 279, 32483-32491.

Hashimoto, T., Wen, G., Lawton, M.T., Boudreau, N.J., Bollen, A.W., Yang, G.Y., Barbaro, N.M., Higashida, R.T., Dowd, C.F., Halbach, V.V., et al. (2003). Abnormal expression of matrix metalloproteinases and tissue inhibitors of metalloproteinases in brain arteriovenous malformations. Stroke 34, 925-931.

Hecht, J.T., Nelson, L.D., Crowder, E., Wang, Y., Elder, F.F., Harrison, W.R., Francomano, C.A., Prange, C.K., Lennon, G.G., Deere, M., et al. (1995). Mutations in exon 17B of cartilage oligomeric matrix protein (COMP) cause pseudoachondroplasia. Nat Genet 10, 325-329.

Hedbom, E., Antonsson, P., Hjerpe, A., Aeschlimann, D., Paulsson, M., Rosa-Pimentel, E., Sommarin, Y., Wendel, M., Oldberg, A., and
Heinegard, D. (1992). Cartilage matrix proteins. An acidic oligomeric protein (COMP) detected only in cartilage. J Biol Chem 267, 6132-6136.

Herrero-Beaumont, G., Ivorra, J.A., Del Carmen Trabado, M., Blanco, F.J., Benito, P., Martin-Mola, E., Paulino, J., Marenco, J.L., Porto, A., Laffon, A., et al. (2007). Glucosamine sulfate in the treatment of knee osteoarthritis symptoms: a randomized, double-blind, placebo-controlled study using acetaminophen as a side comparator. Arthritis Rheum 56, 555-567.

Hong, S.J., and Kang, K.W. (1999). Purification of granulin-like polypeptide from the blood-sucking leech, Hirudo nipponia. Protein Expr Purif 16, 340-346.

Hovinga, J.A., Studt, J.D., Alberio, L., and Lammle, B. (2004). von Willebrand factor-cleaving protease (ADAMTS-13) activity determination in the diagnosis of thrombotic microangiopathies: the Swiss experience. Semin Hematol 41, 75-82.

Ilic, M.Z., East, C.J., Rogerson, F.M., Fosang, A.J., and Handley, C.J. (2007). Distinguishing aggrecan loss from aggrecan proteolysis in ADAMTS-4 and ADAMTS-5 single and double deficient mice. J Biol Chem 282, 37420-37428.

Imada, K., Lin, N., Liu, C., Lu, A., Chen, W., Yano, M., Sato, T., and Ito, A. (2008). Nobiletin, a citrus polymethoxy flavonoid, suppresses gene expression and production of aggrecanases- 1 and -2 in collagen-induced arthritic mice. Biochem Biophys Res Commun 373, 181-185.

Jones, G.C., and Riley, G.P. (2005). ADAMTS proteinases: a multidomain, multi-functional family with roles in extracellular matrix turnover and arthritis. Arthritis Res Ther 7, 160-169.

Jonsson-Rylander, A.C., Nilsson, T., Fritsche-Danielson, R., Hammarstrom, A., Behrendt, M., Andersson, J.O., Lindgren, K., Andersson, A.K., Wallbrandt, P., Rosengren, B., et al. (2005). Role of ADAMTS-1 in atherosclerosis: remodeling of carotid artery, immunohistochemistry, and proteolysis of versican. Arterioscler Thromb Vasc Biol 25, 180-185.

Kashiwagi, M., Enghild, J.J., Gendron, C., Hughes, C., Caterson, B., Itoh, Y., and Nagase, H. (2004). Altered proteolytic activities of ADAMTS-4 expressed by C-terminal processing. J Biol Chem 279 , 10109-10119.

Kashiwagi, M., Tortorella, M., Nagase, H., and Brew, K. (2001). TIMP3 is a potent inhibitor of aggrecanase 1 (ADAM-TS4) and aggrecanase 2 (ADAM-TS5). J Biol Chem 276, 12501-12504.

Kramerova, I.A., Kawaguchi, N., Fessler, L.I., Nelson, R.E., Chen, Y., Kramerov, A.A., Kusche-Gullberg, M., Kramer, J.M., Ackley, B.D., Sieron, A.L., et al. (2000). Papilin in development; a pericellular protein with a homology to the ADAMTS metalloproteinases. Development 127, 5475-5485.

Kraus, V.B., Huebner, J.L., Fink, C., King, J.B., Brown, S., Vail, T.P., and Guilak, F. (2002). Urea as a passive transport marker for arthritis biomarker studies. Arthritis Rheum 46, 420- 427.

Kuno, K., Okada, Y., Kawashima, H., Nakamura, H., Miyasaka, M., Ohno, H., and Matsushima, K. (2000). ADAMTS-1 cleaves a cartilage proteoglycan, aggrecan. FEBS Lett 478, 241-245.

Lark, M.W., Bayne, E.K., Flanagan, J., Harper, C.F., Hoerrner, L.A., Hutchinson, N.I., Singer, II, Donatelli, S.A., Weidner, J.R., Williams, H.R., et al. (1997). Aggrecan degradation in human cartilage. Evidence for both matrix metalloproteinase and aggrecanase activity in normal, osteoarthritic, and rheumatoid joints. J Clin Invest 100, 93-106.

Levy, G.G., Nichols, W.C., Lian, E.C., Foroud, T., McClintick, J.N., 
McGee, B.M., Yang, A.Y., Siemieniak, D.R., Stark, K.R., Gruppo, R., et al. (2001). Mutations in a member of the ADAMTS gene family cause thrombotic thrombocytopenic purpura. Nature 413 , $488-494$.

Li, Z., Nardi, M.A., Li, Y.S., Zhang, W., Pan, R., Dang, S., Yee, H., Quartermain, D., Jonas, S., and Karpatkin, S. (2009). C-terminal ADAMTS-18 fragment induces oxidative platelet fragmentation, dissolves platelet aggregates, and protects against carotid artery occlusion and cerebral stroke. Blood 113, 6051-6060.

Lind, T., McKie, N., Wendel, M., Racey, S.N., and Birch, M.A. (2005). The hyalectan degrading ADAMTS-1 enzyme is expressed by osteoblasts and up-regulated at regions of new bone formation. Bone 36, 408-417.

Little, C.B., Meeker, C.T., Golub, S.B., Lawlor, K.E., Farmer, P.J., Smith, S.M., and Fosang, A.J. (2007). Blocking aggrecanase cleavage in the aggrecan interglobular domain abrogates cartilage erosion and promotes cartilage repair. J Clin Invest 117 , $1627-1636$.

Liu, C.J. (2009). The role of ADAMTS-7 and ADAMTS-12 in the pathogenesis of arthritis. Nat Clin Pract Rheumatol 5, 38-45.

Liu, C.J., Kong, W., Ilalov, K., Yu, S., Xu, K., Prazak, L., Fajardo, M., Sehgal, B., and Di Cesare, P.E. (2006a). ADAMTS-7: a metalloproteinase that directly binds to and degrades cartilage oligomeric matrix protein. FASEB J 20, 988-990.

Liu, C.J., Kong, W., Xu, K., Luan, Y., llalov, K., Sehgal, B., Yu, S., Howell, R.D., and Di Cesare, P.E. (2006b). ADAMTS-12 associates with and degrades cartilage oligomeric matrix protein. $\mathrm{J}$ Biol Chem 281, 15800-15808.

Llamazares, M., Cal, S., Quesada, V., and Lopez-Otin, C. (2003). Identification and characterization of ADAMTS-20 defines a novel subfamily of metalloproteinases-disintegrins with multiple thrombospondin-1 repeats and a unique GON domain. J Biol Chem 278, 13382-13389.

Llamazares, M., Obaya, A.J., Moncada-Pazos, A., Heljasvaara, R., Espada, J., Lopez-Otin, C., and Cal, S. (2007). The ADAMTS12 metalloproteinase exhibits anti-tumorigenic properties through modulation of the Ras-dependent ERK signalling pathway. J Cell Sci 120, 3544-3552.

Lohmander, L.S., lonescu, M., Jugessur, H., and Poole, A.R. (1999). Changes in joint cartilage aggrecan after knee injury and in osteoarthritis. Arthritis Rheum 42, 534-544.

Lu, R., and Serrero, G. (2000). Inhibition of PC cell-derived growth factor (PCDGF, epithelin/granulin precursor) expression by antisense PCDGF cDNA transfection inhibits tumorigenicity of the human breast carcinoma cell line MDA-MB-468. Proc Natl Acad Sci U S A 97, 3993-3998.

Luan, Y., Kong, L., Howell, D.R., Ilalov, K., Fajardo, M., Bai, X.H., Di Cesare, P.E., Goldring, M.B., Abramson, S.B., and Liu, C.J. (2008). Inhibition of ADAMTS-7 and ADAMTS-12 degradation of cartilage oligomeric matrix protein by alpha-2-macroglobulin. Osteoarthritis Cartilage 16, 1413-1420.

Luque, A., Carpizo, D.R., and Iruela-Arispe, M.L. (2003). ADAMTS1/ METH1 inhibits endothelial cell proliferation by direct binding and sequestration of VEGF165. J Biol Chem 278, 23656-23665.

Mahmoodi, M., Sahebjam, S., Smookler, D., Khokha, R., and Mort, J. S. (2005). Lack of tissue inhibitor of metalloproteinases-3 results in an enhanced inflammatory response in antigen-induced arthritis. Am J Pathol 166, 1733-1740.

Majerus, E.M., Zheng, X., Tuley, E.A., and Sadler, J.E. (2003).
Cleavage of the ADAMTS13 propeptide is not required for protease activity. J Biol Chem 278, 46643-46648.

Majumdar, M.K., Askew, R., Schelling, S., Stedman, N., Blanchet, T., Hopkins, B., Morris, E.A., and Glasson, S.S. (2007). Doubleknockout of ADAMTS-4 and ADAMTS-5 in mice results in physiologically normal animals and prevents the progression of osteoarthritis. Arthritis Rheum 56, 3670-3674.

Malemud, C.J. (2006). Matrix metalloproteinases (MMPs) in health and disease: an overview. Front Biosci 11, 1696-1701.

Malfait, A.M., Arner, E.C., Song, R.H., Alston, J.T., Markosyan, S., Staten, N., Yang, Z., Griggs, D.W., and Tortorella, M.D. (2008). Proprotein convertase activation of aggrecanases in cartilage in situ. Arch Biochem Biophys 478, 43-51.

Malfait, A.M., Liu, R.Q., Ijiri, K., Komiya, S., and Tortorella, M.D. (2002). Inhibition of ADAM-TS4 and ADAM-TS5 prevents aggrecan degradation in osteoarthritic cartilage. J Biol Chem 277, 22201-22208.

Mansson, B., Carey, D., Alini, M., Ionescu, M., Rosenberg, L.C., Poole, A.R., Heinegard, D., and Saxne, T. (1995). Cartilage and bone metabolism in rheumatoid arthritis. Differences between rapid and slow progression of disease identified by serum markers of cartilage metabolism. J Clin Invest 95, 1071-1077.

Martel-Pelletier, J., Welsch, D.J., and Pelletier, J.P. (2001). Metalloproteases and inhibitors in arthritic diseases. Best Pract Res Clin Rheumato I 15, 805-829.

Melching, L.I., Fisher, W.D., Lee, E.R., Mort, J.S., and Roughley, P.J. (2006). The cleavage of biglycan by aggrecanases. Osteoarthritis Cartilage 14, 1147-1154.

Misumi, K., Vilim, V., Hatazoe, T., Murata, T., Fujiki, M., Oka, T., Sakamoto, H., and Carter, S.D. (2002). Serum level of cartilage oligomeric matrix protein (COMP) in equine osteoarthritis. Equine Vet J 34, 602-608.

Mittaz, L., Ricardo, S., Martinez, G., Kola, I., Kelly, D.J., Little, M.H., Hertzog, P.J., and Pritchard, M.A. (2005). Neonatal calyceal dilation and renal fibrosis resulting from loss of Adamts- 1 in mouse kidney is due to a developmental dysgenesis. Nephrol Dial Transplant 20, 419-423.

Mittaz, L., Russell, D.L., Wilson, T., Brasted, M., Tkalcevic, J., Salamonsen, L.A., Hertzog, P.J., and Pritchard, M.A. (2004). Adamts-1 is essential for the development and function of the urogenital system. Biol Reprod 70, 1096-1105.

Moake, J.L. (2004). von Willebrand factor, ADAMTS-13, and thrombotic thrombocytopenic purpura. Semin Hematol 41, 4-14.

Moriguchi-Goto, S., Yamashita, A., Tamura, N., Soejima, K., Takahashi, M., Nakagaki, T., Goto, S., and Asada, Y. (2009). ADAMTS-13 attenuates thrombus formation on type I collagen surface and disrupted plaques under flow conditions. Atherosclerosis 203, 409-416.

Murphy, G., and Lee, M.H. (2005). What are the roles of metalloproteinases in cartilage and bone damage? Ann Rheum Dis 64 Suppl 4, iv44- 47.

Murphy, G., and Nagase, H. (2008). Reappraising metalloproteinases in rheumatoid arthritis and osteoarthritis: destruction or repair? Nat Clin Pract Rheumato I 4, 128-135.

Naito, S., Shiomi, T., Okada, A., Kimura, T., Chijiiwa, M., Fujita, Y., Yatabe, T., Komiya, K., Enomoto, H., Fujikawa, K., et al. (2007). Expression of ADAMTS4 (aggrecanase-1) in human osteoarthritic cartilage. Pathol Int 57, 703-711.

Nakada, M., Miyamori, H., Kita, D., Takahashi, T., Yamashita, J., Sato, 
H., Miura, R., Yamaguchi, Y., and Okada, Y. (2005). Human glioblastomas overexpress ADAMTS-5 that degrades brevican. Acta Neuropathol 110, 239-246.

Nakamura, A., Sakai, Y., Ohata, C., and Komurasaki, T. (2007). Expression and significance of a disintegrin and metalloproteinase with thrombospondin motifs (ADAMTS)-1 in an animal model of renal interstitial fibrosis induced by unilateral ureteral obstruction. Exp Toxicol Pathol 59, 1-7.

Neidhart, M. (1996). Elevated serum prolactin or elevated prolactin/ cortisol ratio are associated with autoimmune processes in systemic lupus erythematosus and other connective tissue diseases. J Rheumatol 23, 476-481.

Neidhart, M., Hauser, N., Paulsson, M., DiCesare, P.E., Michel, B.A., and Hauselmann, H.J. (1997). Small fragments of cartilage oligomeric matrix protein in synovial fluid and serum as markers for cartilage degradation. Br J Rheumatol 36, 1151-1160.

Nicholson, A.C., Malik, S.B., Logsdon, J.M., Jr., and Van Meir, E.G. (2005). Functional evolution of ADAMTS genes: evidence from analyses of phylogeny and gene organization. BMC Evol Biol 5, 11.

Ong, C.H., and Bateman, A. (2003). Progranulin (granulin-epithelin precursor, $\mathrm{PC}$-cell derived growth factor, acrogranin) in proliferation and tumorigenesis. Histol Histopathol 18, 1275-1288.

Plaas, A., Osborn, B., Yoshihara, Y., Bai, Y., Bloom, T., Nelson, F., Mikecz, K., and Sandy, J.D. (2007). Aggrecanolysis in human osteoarthritis: confocal localization and biochemical characterization of ADAMTS5-hyaluronan complexes in articular cartilages. Osteoarthritis Cartilage 15, 719-734.

Porter, S., Clark, I.M., Kevorkian, L., and Edwards, D.R. (2005). The ADAMTS metalloproteinases. Biochem J 386, 15-27.

Pratta, M.A., Scherle, P.A., Yang, G., Liu, R.Q., and Newton, R.C. (2003a). Induction of aggrecanase 1 (ADAM-TS4) by interleukin-1 occurs through activation of constitutively produced protein. Arthritis Rheum 48, 119-133.

Pratta, M.A., Yao, W., Decicco, C., Tortorella, M.D., Liu, R.Q., Copeland, R.A., Magolda, R., Newton, R.C., Trzaskos, J.M., and Arner, E.C. (2003b). Aggrecan protects cartilage collagen from proteolytic cleavage. J Biol Chem 278, 45539-45545.

Rees, S.G., Flannery, C.R., Little, C.B., Hughes, C.E., Caterson, B., and Dent, C.M. (2000). Catabolism of aggrecan, decorin and biglycan in tendon. Biochem J $350 \mathrm{Pt}$ 1, 181-188.

Reginster, J.Y. (2007). The efficacy of glucosamine sulfate in osteoarthritis: financial and nonfinancial conflict of interest. Arthritis Rheum 56, 2105-2110.

Rehn, A.P., Birch, M.A., Karlstrom, E., Wendel, M., and Lind, T. (2007). ADAMTS-1 increases the three-dimensional growth of osteoblasts through type I collagen processing. Bone 41, 231-238.

Rintelen, B., Neumann, K., and Leeb, B.F. (2006). A meta-analysis of controlled clinical studies with diacerein in the treatment of osteoarthritis. Arch Intern Med 166, 1899-1906.

Roach, H.I., Yamada, N., Cheung, K.S., Tilley, S., Clarke, N.M., Oreffo, R.O., Kokubun, S., and Bronner, F. (2005). Association between the abnormal expression of matrix-degrading enzymes by human osteoarthritic chondrocytes and demethylation of specific CpG sites in the promoter regions. Arthritis Rheum 52, 3110-3124.

Rocks, N., Paulissen, G., Quesada-Calvo, F., Munaut, C., Gonzalez, M.L., Gueders, M., Hacha, J., Gilles, C., Foidart, J.M., Noel, A., et al. (2008). ADAMTS-1 metalloproteinase promotes tumor development through the induction of a stromal reaction in vivo. Cancer Res 68, 9541-9550.
Rodriguez-Lopez, J., Mustafa, Z., Pombo-Suarez, M., Malizos, K.N., Rego, I., Blanco, F.J., Tsezou, A., Loughlin, J., Gomez-Reino, J.J., and Gonzalez, A. (2008). Genetic variation including nonsynonymous polymorphisms of a major aggrecanase, ADAMTS-5, in susceptibility to osteoarthritis. Arthritis Rheum 58, 435-441.

Rodriguez-Lopez, J., Pombo-Suarez, M., Loughlin, J., Tsezou, A., Blanco, F.J., Meulenbelt, I., Slagboom, P.E., Valdes, A.M., Spector, T.D., Gomez-Reino, J.J., et al. (2009). Association of a nsSNP in ADAMTS14 to some osteoarthritis phenotypes. Osteoarthritis Cartilage 17, 321-327.

Rodriguez-Manzaneque, J.C., Milchanowski, A.B., Dufour, E.K., Leduc, R., and Iruela-Arispe, M.L. (2000). Characterization of METH-1/ADAMTS1 processing reveals two distinct active forms. J Biol Chem 275, 33471-33479.

Rosenberg, K., Olsson, H., Morgelin, M., and Heinegard, D. (1998). Cartilage oligomeric matrix protein shows high affinity zincdependent interaction with triple helical collagen. J Biol Chem 273, 20397-20403.

Roughley, P.J. (2001). Articular cartilage and changes in arthritis: noncollagenous proteins and proteoglycans in the extracellular matrix of cartilage. Arthritis Res 3, 342-347.

Rowan, A.D., Litherland, G.J., Hui, W., and Milner, J.M. (2008). Metalloproteases as potential therapeutic targets in arthritis treatment. Expert Opin Ther Targets 12, 1-18.

Roy, R., Louis, G., Loughlin, K.R., Wiederschain, D., Kilroy, S.M., Lamb, C.C., Zurakowski, D., and Moses, M.A. (2008). Tumorspecific urinary matrix metalloproteinase fingerprinting: identification of high molecular weight urinary matrix metalloproteinase species. Clin Cancer Res 14, 6610-6617.

Sabatine, M.S., Ploughman, L., Simonsen, K.L., lakoubova, O.A., Kirchgessner, T.G., Ranade, K., Tsuchihashi, Z., Zerba, K.E., Long, D.U., Tong, C.H., et al. (2008). Association between ADAMTS1 matrix metalloproteinase gene variation, coronary heart disease, and benefit of statin therapy. Arterioscler Thromb Vasc Biol 28, 562-567.

Sahebjam, S., Khokha, R., and Mort, J.S. (2007). Increased collagen and aggrecan degradation with age in the joints of Timp3(-/-) mice. Arthritis Rheum 56, 905-909.

Sandy, J.D. (2003). A contentious issue finds some clarity: on the independent and complementary roles of aggrecanase activity and MMP activity in human joint aggrecanolysis. Osteoarthritis Cartilage 14, 95-100.

Sandy, J.D., Flannery, C.R., Neame, P.J., and Lohmander, L.S. (1992). The structure of aggrecan fragments in human synovial fluid. Evidence for the involvement in osteoarthritis of a novel proteinase which cleaves the Glu 373-Ala 374 bond of the interglobular domain. J Clin Invest 89, 1512-1516.

Sandy, J.D., Gamett, D., Thompson, V., and Verscharen, C. (1998). Chondrocyte-mediated catabolism of aggrecan: aggrecanasedependent cleavage induced by interleukin-1 or retinoic acid can be inhibited by glucosamine. Biochem J 335 Pt 1, 59-66.

Sandy, J.D., and Verscharen, C. (2001). Analysis of aggrecan in human knee cartilage and synovial fluid indicates that aggrecanase (ADAMTS) activity is responsible for the catabolic turnover and loss of whole aggrecan whereas other protease activity is required for C-terminal processing in vivo. Biochem J 358, 615-626.

Sawaji, Y., Hynes, J., Vincent, T., and Saklatvala, J. (2008). Fibroblast growth factor 2 inhibits induction of aggrecanase activity in human 
articular cartilage. Arthritis Rheum 58, 3498-3509.

Saxne, T., and Heinegard, D. (1992). Cartilage oligomeric matrix protein: a novel marker of cartilage turnover detectable in synovial fluid and blood. Br J Rheumatol 31, 583-591.

Shenkman, B. (2006). The role of ADAMT-13 in platelet adhesion in flow: methods for diagnosis of thrombotic thrombocytopenic purpura. Pathophysiol Haemost Thromb 35, 98-102.

Shindo, T., Kurihara, H., Kuno, K., Yokoyama, H., Wada, T., Kurihara, Y., Imai, T., Wang, Y., Ogata, M., Nishimatsu, H., et al. (2000). ADAMTS-1: a metalloproteinase-disintegrin essential for normal growth, fertility, and organ morphology and function. J Clin Invest 105, 1345-1352.

Shozu, M., Minami, N., Yokoyama, H., Inoue, M., Kurihara, H., Matsushima, K., and Kuno, K. (2005). ADAMTS-1 is involved in normal follicular development, ovulatory process and organization of the medullary vascular network in the ovary. $\mathrm{J}$ Mol Endocrinol 35, 343-355.

Somerville, R.P., Longpre, J.M., Apel, E.D., Lewis, R.M., Wang, L.W., Sanes, J.R., Leduc, R., and Apte, S.S. (2004). ADAMTS7B, the full-length product of the ADAMTS7 gene, is a chondroitin sulfate proteoglycan containing a mucin domain. J Biol Chem 279, 35159-35175.

Somerville, R.P., Longpre, J.M., Jungers, K.A., Engle, J.M., Ross, M., Evanko, S., Wight, T.N., Leduc, R., and Apte, S.S. (2003). Characterization of ADAMTS- 9 and ADAMTS-20 as a distinct ADAMTS subfamily related to Caenorhabditis elegans GON-1. J Biol Chem 278, 9503-9513.

Song, R.H., Tortorella, M.D., Malfait, A.M., Alston, J.T., Yang, Z., Arner, E.C., and Griggs, D.W. (2007). Aggrecan degradation in human articular cartilage explants is mediated by both ADAMTS-4 and ADAMTS-5. Arthritis Rheum 56, 575-585.

Stanton, H., Rogerson, F.M., East, C.J., Golub, S.B., Lawlor, K.E., Meeker, C.T., Little, C.B., Last, K., Farmer, P.J., Campbell, I.K., et al. (2005). ADAMTS5 is the major aggrecanase in mouse cartilage in vivo and in vitro. Nature 434, 648-652.

Stracke, J.O., Fosang, A.J., Last, K., Mercuri, F.A., Pendas, A.M., Llano, E., Perris, R., Di Cesare, P.E., Murphy, G., and Knauper, V. (2000). Matrix metalloproteinases 19 and 20 cleave aggrecan and cartilage oligomeric matrix protein (COMP). FEBS Lett 478, 52-56.

Sugimoto, K., Takahashi, M., Yamamoto, Y., Shimada, K., and Tanzawa, K. (1999). Identification of aggrecanase activity in medium of cartilage culture. J Biochem 126, 449-455.

Takizawa, M., Yatabe, T., Okada, A., Chijiiwa, M., Mochizuki, S., Ghosh, P., and Okada, Y. (2008). Calcium pentosan polysulfate directly inhibits enzymatic activity of ADAMTS4 (aggrecanase-1) in osteoarthritic chondrocytes. FEBS Lett 582, 2945-2949.

Tang, B.L. (2001). ADAMTS: a novel family of extracellular matrix proteases. Int J Biochem Cell Biol 33, 33-44.

Thompson, J.D., Higgins, D.G., and Gibson, T.J. (1994). CLUSTAL W: improving the sensitivity of progressive multiple sequence alignment through sequence weighting, position-specific gap penalties and weight matrix choice. Nucleic Acids Res 22, 4673-4680.

Tkachenko, E., Rhodes, J.M., and Simons, M. (2005). Syndecans: new kids on the signaling block. Circ Res 96, 488-500.

Tortorella, M., Pratta, M., Liu, R.Q., Abbaszade, I., Ross, H., Burn, T., and Arner, E. (2000a). The thrombospondin motif of aggrecanase1 (ADAMTS-4) is critical for aggrecan substrate recognition and cleavage. J Biol Chem 275, 25791-25797.

Tortorella, M.D., Arner, E.C., Hills, R., Easton, A., Korte-Sarfaty, J.,
Fok, K., Wittwer, A.J., Liu, R.Q., and Malfait, A.M. (2004). Alpha2macroglobulin is a novel substrate for ADAMTS-4 and ADAMTS-5 and represents an endogenous inhibitor of these enzymes. J Biol Chem 279, 17554-17561.

Tortorella, M.D., Burn, T.C., Pratta, M.A., Abbaszade, I., Hollis, J.M., Liu, R., Rosenfeld, S.A., Copeland, R.A., Decicco, C.P., Wynn, R., et al. (1999). Purification and cloning of aggrecanase-1: a member of the ADAMTS family of proteins. Science 284, 1664-1666.

Tortorella, M.D., and Malfait, A.M. (2008). Will the real aggrecanase (s) step up: evaluating the criteria that define aggrecanase activity in osteoarthritis. Curr Pharm Biotechnol 9, 16-23.

Tortorella, M.D., Malfait, A.M., Deccico, C., and Arner, E. (2001). The role of ADAM-TS4 (aggrecanase-1) and ADAM-TS5 (aggrecanase-2) in a model of cartilage degradation. Osteoarthritis Cartilage 9, 539-552.

Tortorella, M.D., Pratta, M., Liu, R.Q., Austin, J., Ross, O.H., Abbaszade, I., Burn, T., and Arner, E. (2000b). Sites of aggrecan cleavage by recombinant human aggrecanase-1 (ADAMTS-4). J Biol Chem 275, 18566-18573.

Troeberg, L., Fushimi, K., Khokha, R., Emonard, H., Ghosh, P., and Nagase, H. (2008). Calcium pentosan polysulfate is a multifaceted exosite inhibitor of aggrecanases. FASEB J 22, 3515-3524.

Tsuzaki, M., Guyton, G., Garrett, W., Archambault, J.M., Herzog, W., Almekinders, L., Bynum, D., Yang, X., and Banes, A.J. (2003). IL-1 beta induces COX2, MMP-1, -3 and -13 , ADAMTS-4, IL-1 beta and IL-6 in human tendon cells. J Orthop Res 21, 256-264.

Vankemmelbeke, M.N., Holen, I., Wilson, A.G., Ilic, M.Z., Handley, C. J., Kelner, G.S., Clark, M., Liu, C., Maki, R.A., Burnett, D., et al. (2001). Expression and activity of ADAMTS-5 in synovium. Eur J Biochem 268, 1259-1268.

Vazquez, F., Hastings, G., Ortega, M.A., Lane, T.F., Oikemus, S., Lombardo, M., and Iruela-Arispe, M.L. (1999). METH-1, a human ortholog of ADAMTS-1, and METH-2 are members of a new family of proteins with angio-inhibitory activity. J Biol Chem 274, 23349-23357.

Vlad, S.C., LaValley, M.P., McAlindon, T.E., and Felson, D.T. (2007). Glucosamine for pain in osteoarthritis: why do trial results differ? Arthritis Rheum 56, 2267-2277.

Voros, G., Maquoi, E., Collen, D., and Lijnen, H.R. (2003). Differential expression of plasminogen activator inhibitor-1, tumor necrosis factor-alpha, TNF-alpha converting enzyme and ADAMTS family members in murine fat territories. Biochim Biophys Acta 1625, $36-42$.

Wagsater, D., Bjork, H., Zhu, C., Bjorkegren, J., Valen, G., Hamsten, A., and Eriksson, P. (2008). ADAMTS-4 and -8 are inflammatory regulated enzymes expressed in macrophage-rich areas of human atherosclerotic plaques. Atherosclerosis 196, 514-522.

Wayne, G.J., Deng, S.J., Amour, A., Borman, S., Matico, R., Carter, H. L., and Murphy, G. (2007). TIMP-3 inhibition of ADAMTS-4 (Aggrecanase-1) is modulated by interactions between aggrecan and the C-terminal domain of ADAMTS-4. J Biol Chem 282, 20991-20998.

Westling, J., Fosang, A.J., Last, K., Thompson, V.P., Tomkinson, K.N., Hebert, T., McDonagh, T., Collins-Racie, L.A., LaVallie, E.R., Morris, E.A., et al. (2002). ADAMTS4 cleaves at the aggrecanase site (Glu373-Ala374) and secondarily at the matrix metalloproteinase site (Asn341-Phe342) in the aggrecan interglobular domain. J Biol Chem 277, 16059-16066.

Wiberg, C., Hedbom, E., Khairullina, A., Lamande, S.R., Oldberg, A., 
Timpl, R., Morgelin, M., and Heinegard, D. (2001). Biglycan and decorin bind close to the $n$-terminal region of the collagen $\mathrm{VI}$ triple helix. J Biol Chem 276, 18947-18952.

Wiberg, C., Heinegard, D., Wenglen, C., Timpl, R., and Morgelin, M. (2002). Biglycan organizes collagen VI into hexagonal-like networks resembling tissue structures. J Biol Chem 277, 49120-49126.

Wright, W.E., Sassoon, D.A., and Lin, V.K. (1989). Myogenin, a factor regulating myogenesis, has a domain homologous to MyoD. Cell $56,607-617$.

Xu, K., Zhang, Y., Ilalov, K., Carlson, C.S., Feng, J.Q., Di Cesare, P.E., and Liu, C.J. (2007). Cartilage oligomeric matrix protein associates with granulin-epithelin precursor (GEP) and potentiates GEPstimulated chondrocyte proliferation. J Biol Chem 282, 11347-11355.

Yamanishi, Y., Boyle, D.L., Clark, M., Maki, R.A., Tortorella, M.D., Arner, E.C., and Firestein, G.S. (2002). Expression and regulation of aggrecanase in arthritis: the role of TGF-beta. J Immunol 168, 1405-1412.

Yasumoto, T., Bird, J.L., Sugimoto, K., Mason, R.M., and Bayliss, M.T. (2003). The G1 domain of aggrecan released from porcine articular cartilage forms stable complexes with hyaluronan/link protein. Rheumatology 42, 336-342.

Yatabe, T., Mochizuki, S., Takizawa, M., Chijiiwa, M., Okada, A., Kimura, T., Fujita, Y., Matsumoto, H., Toyama, Y., and Okada, Y.
(2009). Hyaluronan inhibits expression of ADAMTS4 (aggrecanase-1) in human osteoarthritic chondrocytes. Ann Rheum Dis 68, 1051-1058.

Yaykasli, K.O., Oohashi, T., Hirohata, S., Hatipoglu, O.F., Inagawa, K., Demircan, K., and Ninomiya, Y. (2009). ADAMTS9 activation by interleukin 1 beta via NFATc1 in OUMS-27 chondrosarcoma cells and in human chondrocytes. Mol Cell Biochem 323, 69-79.

Zanocco-Marani, T., Bateman, A., Romano, G., Valentinis, B., He, Z. $H_{\text {., }}$ and Baserga, R. (1999). Biological activities and signaling pathways of the granulin/epithelin precursor. Cancer Res 59, 5331-5340.

Zhang, W., Moskowitz, R.W., Nuki, G., Abramson, S., Altman, R.D., Arden, N., Bierma-Zeinstra, S., Brandt, K.D., Croft, P., Doherty, M., et al. (2007). OARSI recommendations for the management of hip and knee osteoarthritis, part I: critical appraisal of existing treatment guidelines and systematic review of current research evidence. Osteoarthritis Cartilage 15, 981-1000.

Zhou, J., Gao, G., Crabb, J.W., and Serrero, G. (1993). Purification of an autocrine growth factor homologous with mouse epithelin precursor from a highly tumorigenic cell line. J Biol Chem 268, 10863-10869.

Zhu, J., Nathan, C., Jin, W., Sim, D., Ashcroft, G.S., Wahl, S.M., Lacomis, L., Erdjument-Bromage, H., Tempst, P., Wright, C.D., et al. (2002). Conversion of proepithelin to epithelins: roles of SLPI and elastase in host defense and wound repair. Cell 111, 867-878. 